Journal of Systems Science and Information

Oct., 2016, Vol. 4, No. 5, pp. 419-427

DOI: $10.21078 /$ JSSI-2016-419-09

\title{
Empirical Analysis in the Relationship Between the Consumption and Economic Growth Based on the Structural Equation Model
}

\author{
Erxin ZHANG \\ School of Mathematics and Statistics, Central South University, Changsha 410083, China \\ E-mail: zhangerxin6666@163.com \\ Wancai YANG \\ Zhengzhou University of Industrial Technology, Zhengzhou 451100, China \\ E-mail: wancaiy-001@163.com
}

\begin{abstract}
This paper constructs the relationship between consumption and economic growth by a structure equation model and uses the provincial panel data of 29 provinces (municipalities, autonomous regions) from 1992 to 2010 in China, using maximum likelihood estimation method to analyze empirically the relationship between the consumption and economic growth in China. The result shows that the path coefficients between consumptions and economic growth are all positive, that suggests the consumption has significant positive effects on the economic growth. Also in this paper, it gives a new try to use a structural equation model to research the relationship between consumption and economic growth.
\end{abstract}

Keywords structure equation model; consumption; economic growth

\section{Introduction}

For a long time, increasingly growing investment and net exports contribute to form the current development mode mainly relying on the investment and export trade to drive and stimulate economic growth. Faced with the global financial crisis, China's economic development mode was confronted with serious challenges. Although the government took massive fiscal stimulus measures, making China's economy bottomed out quickly, however, as the stimulus faded, investment-driven economic growth mode obviously became weak, but the current international economic outlook is still not optimistic, and exports-driven economic growth is no longer sustainable. As the great power to promote economic growth, consumption naturally is an important research direction on economic growth, so the study on the economic impact of consumption will be conducive to carrying out targeted macro-control based on the combination with the characteristics of China's economy development, better and scientifically guiding consumption, optimizing the economic structure, and solving problems about the transformation of our economic development mode. Main results about investigating the relationship between consumption and economic growth by domestic scholars studying consumption are: Ma and Zhang ${ }^{[1]}$ selected the GDP, urban residents' consumption and rural residents' consumption of

Received October 10, 2015, accepted January 7, 2016 
1978-2004 years as the sample data, to do co-integrated analysis and error correction model.

Zhou and Tang ${ }^{[2]}$ described the mechanism of coordination process between investment and consumption, and then used 1995-2007 provincial panel data, according to the investment rate threshold characteristics, conduct the non-linear regression of the consumption growth rate to growth performance. The results showed that: Relying solely on consummation demand to drive the economy will lead to insufficient investment; therefore, long-term economic growth must rely on investment and consumption at the same time. $\mathrm{Li}$ and Yuan ${ }^{[3]}$ established the simultaneous equation model for empirical analysis Chinese investment, consumption and net export demand. Cui ${ }^{[4]}$ used 1997-2009 provincial panel data in 30 provinces (municipalities and autonomous regions) to construct dynamic panel data model concerned about the relationship between consumption and economic growth of Chinese residents, and used Generalized Moment Method (GMM) for empirical analysis regional differences in the relationship between consumption and economic growth in China. The results showed that: Current per capita real GDP in eastern, central and western regions had a significant impact on the current per capita real consumption.

\section{Background and Hypotheses}

The aim of this section is, through a literature review, to consider possible relationships among livelihood consumption, government consumption and economic growth.

\subsection{Livelihood Consumption and Economic Growth}

Here, the livelihood consumption includes household consumption and tourism consumption.

Huang ${ }^{[5]}$ pointed out that the household consumption occupies a pivotal position in China's economic growth, namely that a positive correlation between household consumption and macroeconomic indicators GDP was presented, and the greater the household consumption was, the more the national economy growth can be promoted. Xu and Jin ${ }^{[6]}$ noted that there was a long-term stable relationship between household consumption and economic growth; the consumption can long-term and stably promote economic growth and stimulating consumption, especially the household consumption occupying larger proportion of the total consumption was the effective means for economic growth.

Balaguer ${ }^{[7]}$ studied the long-term effect of inbound tourism in Spain on its economic growth and found that there was long-term equilibrium relationship between tourism economic development and economic growth through co-integrated regression test and causality test. After the co-integrated regression test and causality test on economic growth and domestic tourism revenues, most domestic scholars believed there existed long-term equilibrium relationship between domestic tourism revenues and economic growth ${ }^{[8-10]}$.

\subsection{Government Consumption and Economic Growth}

Mao and Hong ${ }^{[11]}$ showed that government consumption was an important part of total government expenditure, and research on government consumption growth effect will help us fully understand the economic effect of total government expenditure. On the other hand, government consumption was an important part of the total domestic demand, and the expan- 
sion of government consumption to stimulate domestic demand also had important practical significance on the change of China's economic growth mode.

\subsection{Livelihood Consumption and Government Consumption}

Yuan and Yang ${ }^{[12]}$ pointed out that studied on if there existed long-term equilibrium relationship between household consumption, government consumption and economic growth, and if there existed causal relationship between household consumption growth and economic growth, government consumption and economic growth, household consumption growth and government consumption growth would be an important basis for the government to regulate the economy, and develop economic policy.

Several previous studies had shown the relationship between livelihood consumption and economic growth ${ }^{[13-15]}$.

\section{Our Proposed Model and Variable Set}

In the literature review in this section the theoretical connections among relationships livelihood consumption, government consumption and economic growth, as illustrated in Figure 1, have been demonstrated. These interrelationships of all these constructs are incorporated in to the model. The validity of this model and its connections will be the main reason for this research. As mentioned, Figure 1 presents the proposed model with the research aim to ascertain to what extent livelihood consumption and government consumption affect economic growth.

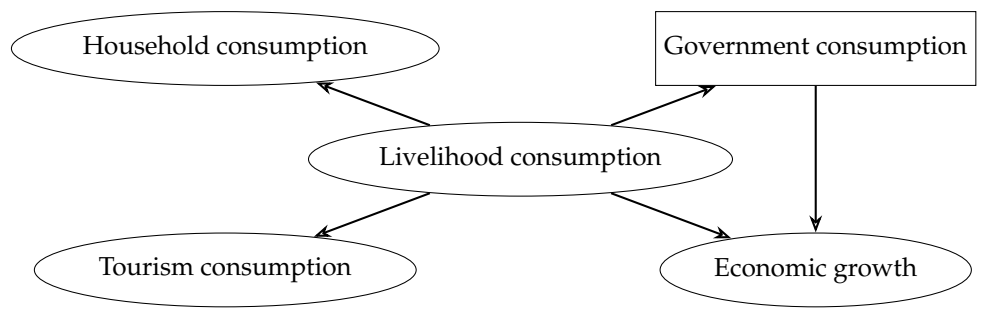

Figure 1 Proposed model for livelihood consumption, government consumption and economic growth

See Table 1 for hypotheses to be investigated in the model, constructs to which each hypothesis refers and measurable variables related to this hypothesis and constructs.

See Table 2 for measurable variables of the proposed model.

In the proposed model, there are two exogenous latent variables: Household consumption and tourism consumption; One second order latent variables: livelihood consumption; One endogenous latent variable: economic growth. Where the first order exogenous latent variables of livelihood consumption are household consumption and tourism consumption; The measurable variables of household consumption are food, clothing, household equipment, health care, transportation and communication, entertainment and culture, living, miscellaneous; The measurable variables of tourism consumption are domestic tourism people, domestic tourism income; The measurable variables of economic growth are the first industry and the tertiary industry; Independent measurable variable is government consumption. 
Table 1 Hypotheses to be investigated in the model, constructs to which each hypothesis refers and measurable variables related to this hypothesis and constructs

\begin{tabular}{lll}
\hline Hypothesis & Constructs & Measurable variables \\
\hline H1 livelihood consumption has a & livelihood consumption & $X 1, X 2, X 3, X 4, X 5, X 6, X 7$, \\
direct, positive effect on economic & & $X 8, X 9, X 10$ \\
growth & economic growth & $X 11, X 12$ \\
H2 livelihood consumption has a & livelihood consumption & $X 1, X 2, X 3, X 4, X 5, X 6, X 7$, \\
direct, positive effect on & & $X 8, X 9, X 10$ \\
government consumption & government consumption & $X 13$ \\
H3 government consumption has a & government consumption & $X 13$ \\
direct, positive effect on economic & economic growth & $X 11, X 12$ \\
growth & & \\
\hline
\end{tabular}

Table 2 Measurable variables of the proposed model

\begin{tabular}{ll}
$X 1$ food & $X 8$ miscellaneous \\
$X 2$ clothing & $X 9$ domestic tourism people \\
$X 3$ household equipment & $X 10$ domestic tourism income \\
$X 4$ health care & $X 11$ the first industry \\
$X 5$ transportation and communication & $X 12$ the tertiary industry \\
$X 6$ entertainment and culture & $X 13$ government consumption \\
$X 7$ living & \\
\hline
\end{tabular}

\section{Data Collection}

In order to study the relationship between consumption and economic growth, according to the statistics caliber from National Bureau of Statistics, with provinces, municipalities and autonomous regions in China as the unit, we collected statistical yearbook data of 31 provinces (municipalities and autonomous regions), and in view of that Tibet Autonomous Region has no data before 1999 and Chongqing has no data before 1997, the analysis in this paper does not include Chongqing and Tibet Autonomous Region.

Unable to conduct scientific questionnaire survey on various provinces (municipalities and autonomous regions), so this paper uses statistical data released by the relevant state departments, specifically from the following sources: Statistical year books of 29 (excluding Tibet and Chongqing) provinces (municipalities and autonomous regions) during 1992-2010, statistics compilation of 60 years since New China, and etc. Ultimately the number of samples is 551, of which the view sample data of household consumption is from urban residents' consumption in the statistical yearbook. 


\section{$5 \quad$ Empirical Results}

\subsection{Model and Analysis}

The statistical methodology used to solve the raised hypotheses will be the causal analysis since it allows to analyze relations of causality between constructs that are not measurable of a direct way, but which they are pronounced through certain observable characteristics. The type of causal analysis used will be the model of structure of covariance also called structural equations model (SEM) and it will be solved with AMOS 17.0.

There are many researches on the relationship between consumption and economic growth ${ }^{[16-18]}$, and main methods include panel data model, regression analysis and simultaneous equations models, etc. No scholars have used structural equation model for research. However, this paper uses structural equation modeling approach to study the relationship between consumption and economic growth. This is a new and innovative method, and it has obvious advantages compared to analytic hierarchy process, factor analysis, and other traditional methods. Analytic hierarchy process can easily lead to subjective assumption, and factor analysis cannot analyze the causality relationship between variables, while structural equation model can make up deficiencies of these methods, as well as to further improve the relationship theory between consumption and economic growth, and enrich the relevant empirical research methods.

In the structural equation model of this study, we examined the two level of analysis - the measurement model and the structure model ${ }^{[19-21]}$.

\subsection{The Results of the Measurement Model}

Table 3 Pearson correlations among measures, standard deviations and covariances

\begin{tabular}{lccccc}
\hline Constructs & Mean & $\begin{array}{c}\text { Standard } \\
\text { deviation }\end{array}$ & $\begin{array}{l}\text { People } \\
\text { consumption }\end{array}$ & $\begin{array}{c}\text { Government } \\
\text { consumption }\end{array}$ & $\begin{array}{c}\text { Economic } \\
\text { growth }\end{array}$ \\
\hline $\begin{array}{l}\text { Livelihood } \\
\text { consumption }\end{array}$ & 2.50 & 0.45 & 1 & 0.921 & 0.939 \\
Government & 5.92 & 0.85 & 0.475 & 1 & 0.992 \\
consumption & 3.28 & 0.99 & 0.250 & 0.678 & 1 \\
Economic growth & & & & 1 \\
\hline Correlations are above the diagonal and covariances are below the diagonal
\end{tabular}

Table 3 shows the means, standard deviations, correlations and covariances matrix of this study. In Table 3 , there are significantly positive correlations among relationships livelihood consumption, government consumption and economic growth. In addition, there are several measurements to confirm the level of reliability and validity (convergent and divergent) of the constructs. One measure of the reliability is to examine the loadings of each of the constructs' individual items. With respect to the quality of the measurements model for the sample, the loadings $\lambda$ of items of the constructs listed in Table 4 are significant and more than $0.5^{[22]}$. Cronbach's alpha is the other measure of the reliability. In agreement with Nunnally (1978), in an exploratory investigation it is required that this coefficient is equal to or greater than 0.7 to be able to affirm that the scale is trustworthy. Table 4 lists Cronbach's alpha for the 
constructs and shows that tourism consumption's is 0.882 , household consumption's is 0.972 and economic growth's is 0.825 . So, all of them are more than 0.7 and the measurement of this study is acceptable in reliability.

Table 4 The loadings $(\lambda)$ of items and Cronbach's $\alpha$ coefficients and AVE's of the constructs

\begin{tabular}{|c|c|c|c|c|}
\hline & Items & Factorial loadings $\lambda i$ & Cronbach's $\alpha$ & AVE \\
\hline \multirow[t]{2}{*}{ Tourism consumption } & $X 12$ & 0.89 & 0.882 & 0.829 \\
\hline & $X 13$ & 0.93 & & \\
\hline \multirow[t]{8}{*}{ Household consumption } & $X 1$ & 0.94 & 0.972 & 0.880 \\
\hline & $X 2$ & 0.88 & & \\
\hline & $X 3$ & 0.95 & & \\
\hline & $X 4$ & 0.98 & & \\
\hline & $X 5$ & 0.96 & & \\
\hline & $X 6$ & 0.97 & & \\
\hline & $X 7$ & 0.90 & & \\
\hline & $X 8$ & 0.92 & & \\
\hline \multirow[t]{2}{*}{ Economic growth } & $X 14$ & 0.99 & 0.825 & 0.647 \\
\hline & $X 15$ & 0.56 & & \\
\hline
\end{tabular}

This study applied Fornell and Larcker's ${ }^{[23]}$ measure of average variance extracted to access the convergent and discriminate validity of measurement. The AVE measures the amount of variance captured by the construct though its items relative to the amount of variance due to the measurement error. To satisfy the requirement of convergent validity the AVE for every construct must be more than $0.5^{[24]}$. This is shown in Table 4, all AVE's are more even than 0.6. So convergent validity is proved. Therefore, the discriminate validity of the measurement in this study is acceptable.

\subsection{The Results of the Structural Model}

This section presents the main result of this research. The use of models SEM allows to adjust better to the work frame that other techniques of more traditional analyses (linear regressions, for example) fundamentally by 2 reasons: Its confirming and nonexploratory approach that allows to contrast previously theorized hypotheses and its capacity to estimate multiple relations for each group of dependent variables.

The tested model with SEM notation is shown in Figure 2.

Overall, the model was judged to be a general fit with the data as most of the fit statistics very well within acceptable levels, except for GFI. As shown at the bottom of Table 5, for example, the comparative fit index (CFI), norm fit index (NFI) and relative fit index (RFI) were greater than 0.9 , root mean square (RMR) was less than 0.05 , root mean square error of approximation (RMSEA) was less than 0.08, but goodness fit index (GFI) was less than 0.9. 


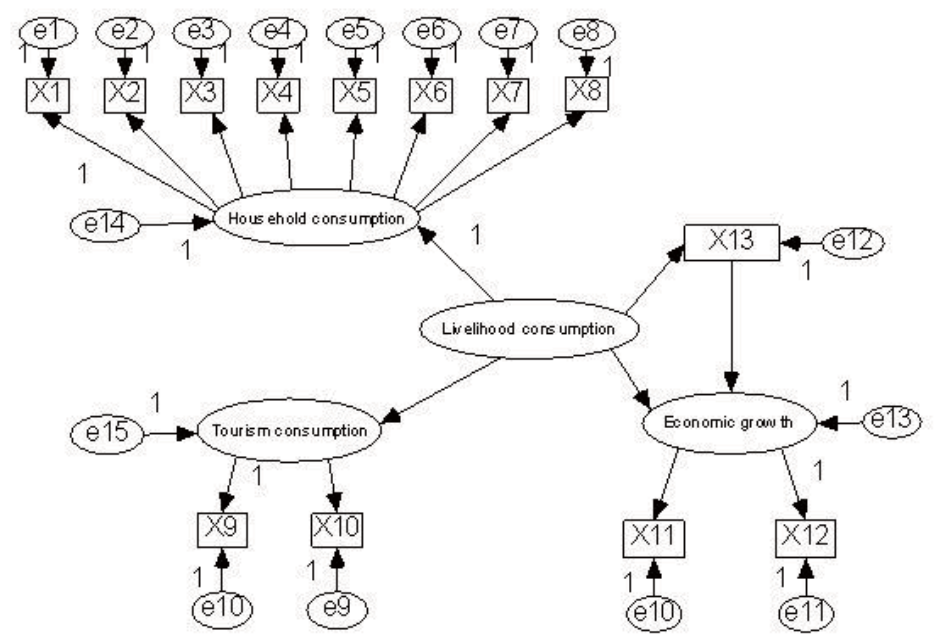

Figure 2 Model of the effects of economic growth on livelihood consumption and government consumption

Table 5 Structural model results: Estimates and model fit

\begin{tabular}{llccc}
\hline Direct effects & Hypothesis & Standardized coefficients $(\beta)$ & S.E. & $p$-value \\
\hline $\begin{array}{l}\text { livelihood consumption- } \\
\text { economic growth }\end{array}$ & H1 & 0.17 & 0.045 & $<0.001$ \\
$\begin{array}{l}\text { livelihood consumption- } \\
\text { government consumption }\end{array}$ & H2 & 0.92 & 0.083 & $<0.001$ \\
government consumption- & & & \\
economic growth & H3 & 0.84 & 0.031 & $<0.001$ \\
& & & \\
Model fit indices & & & \\
CMIN/DF & $2.463(<3)$ & & \\
CFI & $0.949(>0.9)$ & & \\
NFI & $0.945(>0.9)$ & & \\
RFI & $0.923(>0.9)$ & & \\
GFI & $0.862(>0.9)$ & & \\
RMR & $0.038(<0.05)$ & & \\
RMSEA & $0.069(<0.08)$ & & \\
& & & \\
\hline
\end{tabular}

Therefore, government consumption has a significant and positive impact on economic growth $(0.84, p$-value $<0.001)$. The rest of relations is all statistically significant and positive since therefore indicates the $p$-values associated to the regression coefficients. The relation between livelihood consumption and government consumption is the strongest relation (its coefficients 0.92 ) whereas the relations between government consumption and economic growth 
and livelihood consumption and economic growth are weaker (coefficients 0.84 and 0.17 , respectively). There are various types of consumptions, but here we just consider two kinds of consumptions associated with livelihood consumption, therefore, path coefficients of government consumption and livelihood consumption to economic growth are quite different.

Therefore, by way of summary, the main conclusions of the model are presented as it can be seen in Table 6 :

Livelihood consumption influences moderately and in a positive way on economic growth (H1, regression coefficient 0.17 ).

Livelihood consumption influences deeply and in a positive way on government consumption (H2, regression coefficient 0.92 ).

Government consumption influences deeply and in a positive way on economic growth (H3, regression coefficient 0.84 ).

Table 6 Summary of results of the hypotheses

\begin{tabular}{lll}
\hline & Direction and magnitude & Result \\
\hline H1 & Positive and weak & Not rejected \\
H2 & Positive and strong & Not rejected \\
H3 & Positive and strong & Not rejected \\
\hline
\end{tabular}

\section{Conclusion and Suggestion}

Structural equation is the theoretical model used for analyzing and processing relationships involved with multiple reasons and results. This paper uses structural equation for research on relationship between consumption and economic growth. And the result suggests that structural equation can be used to analyze relationship between consumption and economic growth, but also to improve the relationship theory between consumption and economic growth, and enrich empirical research methods for relationship between consumption and economic growth. Through structural equation model, this paper analyzes the relationship between consumption and economic growth, and makes a conclusion that consumption has a role in promoting economic growth, and livelihood consumption (including household consumption and tourism consumption) and government consumption also have a role in promoting economic growth.

In recent years, with China's rapid economic development, people's living standards greatly improved and our consumption also increased, which, to a certain extent, promoted the development of national economy. From the above conclusion, it is known that livelihood consumption and government consumption can promote economic growth, therefore, to promote economic development, and we need to find ways to increase the livelihood and government consumption. However, government consumption is limited, so the key point is to promote the consumption of residents. However, consumption rate of residents is relatively low, so it requires the government to introduce corresponding measures to improve the consumption rate of residents. For example, increase household income, especially the low-income people and farmers, to increase effective demand; promote reform of education and health care, and construction of social security system, and other measures to enhance people's consumption confidence and consumption 
expectations. Then we can raise the consumption level, promote consumption-driven economic growth, transform economic growth mode, so that our economy can maintain the momentum of healthy and rapid development.

\section{References}

[1] Ma C W, Zhang Z P. Analysis of private consumption effects economic development of our country. Finance and Trade Research, 2007(4): 6-11.

[2] Zhou Y H, Tang Z J. The threshold character of investment, consumption improvement and economic growth. Statistical Research, 2009(12): 50-57.

[3] Li Z F, Yuan Z Y. The relationship between consumption, investment, export and economic growth in China. Statistical Research, 2009(2): 41-42.

[4] Cui H Y. Study on regional difference in relationship between residential consumption and economic growth in China. Technology Economics, 2011, 30(2): 98-101.

[5] Huang F N. The relationship between residential consumption and economic growth in China. Economic Observer, 2011(11): 19-21.

[6] Xu F, Jin K Q. An empirical study on the relationship between China residential consumption and economic growth. Journal of Beijing Technology and Business University (Social science), 2009, 24(2): 109-113.

[7] Balaguer J, Cantavalla - Jorda M. Tourism as a long-run economic factor: The Spanish case. Applied Economics, 2002, 34(6): 877-884.

[8] Wu C Y, Xie F Y, Quan Ha. Contribution of tourism development to China's economic growth. ScienceTechnology and Management, 2009, 11(6): 8-11.

[9] Wu G X. Analysis of coherency between tourism development and economic growth in China. Journal of Shanghai Institute of Technology, 2003(4): 238-241.

[10] Liu C S, Jian Y F. Study on the relationship between tourism development and economic growth in China. Tourism Science, 2008, 22(5): 23-31.

[11] Mao Z G, Hong T. Government consumption and economic growth: An empirical study based on panel data of 31 provinces in China from 1985 to 2007. Statistical Research, 2009, 26(8): 24-31.

[12] Yuan X L, Yang W P. Causality between government and private consumption and China economic growth. Modern Economic Science, 2008(5): 49-55.

[13] Zhang L F, Liu B D. Analysis on influence of tourism consumption on economic growth in China. Technology Economics, 2009, 28(5): 81-85.

[14] Fu J Y, Wang J H. The difference of correlation analysis between urban and rural residents' consumption and economic growth. Statistics and Decision, 2010(4): 93-95.

[15] Wang Y, Li S M. Empirical analysis in the relationship between urban residents' consumption structure and economic growth. Statistics and Decision, 2012(10): 133-135.

[16] Que C Y, Ma B. Relationship between households consumption and economic growth in China based on VAR model. Journal of Dalian Maritime University, 2010, 36(4): 68-73.

[17] Liu X H, Jiang K S. The co-integration analysis on the final consumption and economic growth. Journal of Industrial Technological Economics, 2014(12): 66-72.

[18] Zhang Z J, Wu D Y. A retest with respect to relations of consumption, investment, export and economic growth: Based on the partial least square. Journal of Hunan University (Social Sciences), 2011, 25(6): 61-65.

[19] Wu M L. Structural equation model, the operation and application of AMOS. Chongqing Press, 2009.

[20] Hou J T, Wen Z L, Cheng Z J, et al. Structural equation model and its application. Education Science Press, 2004.

[21] Qiu H Z, Lin B F. The principle and application of structural equation model. China Light Industry Press, 2009.

[22] Hair F, Suárez M G. Análisis multivariante. Madrid: Prentice Hall, 1999.

[23] Fornell C, Larcker D F. Evaluating structural equation models with unobservable variables and measurement error. Journal of Marketing Research, 1981, 18(1): 39-50.

[24] Hair J, Black W, Babin B, et al. Multivariate Data Analysis. 7th Edition, 2010. 